\title{
Citología Exfoliativa en el Diagnóstico de Carcinoma de Cuello Uterino
}

\author{
Dr. José Mario Posada Aristizábal \\ Dr. Gonzalo Vásquez Vásquez \\ Del Departamento de Ginecología y Obstetricia \\ de la Universidad de Antioquia
}

Este trabajo comprende la revisión de seiscientos cincuenta casos estudiados personalmente por medio de la citología exfoliativa.

El presente estudio se adelanta en forma sistemática, en pacientes con patología cervico-vaginal, en la mayoría de los casos, y en muchos de ellos, en particular en los últimos meses, para buscar el carcinoma en pacientes que por la edad o, por actividad obstétrica y sin ninguna sintomatología están sometidas a la contingencia de sufrirlo.

\section{MATERIAL Y METODOS}

Las pacientes pertenecen tanto al Instituto Colombiano de Seguros Sociales, como a la clientela privada y el estudio comprende un lapso de tres años.

El método de coloración de los extendidos, ha sido la técnica clásica de Papanicolau, suficientemente conocida por todos.

Las muestras fueron tomadas en la siguiente forma, para cada caso:

1) La muestra vaginal, por aspiración con pipeta de fondo de saco posterior.

2) La muestra cervical comprende dos zonas así:

a) Endocervical, tomada con aplicador de algodón, procurando obtener células de todo el canal y 
b) escamo-columnar, obtenida por raspado circular con la paleta de Ayre. (Biopsia de superficie).

Los resultados se expresan en distintos tipos según lo establecido por Papanicolau y refiriéndose por separado a cada una de las muestras estudiadas.

El estudio dio las siguientes cifras para cada grupo:

\begin{tabular}{|lcc|}
\hline Tipo & Casos & Porcentajes \\
I & 4 & $0.6 \%$ \\
II & 369 & $56.8 \%$ \\
III & 215 & $33.0 \%$ \\
IV & 39 & $6.0 \%$ \\
V & 23 & $3.6 \%$ \\
\hline
\end{tabular}

Los extendidos tipo I y II son negativos para Carcinoma.

$" \quad " \quad$ III son dudosos.

" " $\quad$ IV se interpretan como: fuerte sospecha de malignidad, y

" $\quad$ " V positivo para Carcinoma.

Los tipos I y II por ser negativos, no los analizaremos, pero no obstante podemos advertir que las historias correspondientes fueron estudiadas y no hubo cambio en un lapso de 6 meses.

El tipo III, dudoso, lo clasificamos así por las siguientes razones:

1) Atipias menores.

2) Cambios acentuados de tipo inflamatorio.

3) Hipoestrogenismo marcado.

4) Aquellos en que se encontraron leves cambios celulares sin explicación satisfactoria. dosos.

Todo esto hace aparecer un poco alta la cifra de casos du- 
En este grupo, una vez corregidas las causas determinantes del tipo (Tricomoniasis, cervicitis, hipoestrogenismo), la mayoría se hicieron negativos en controles posteriores.

Siguen dudosos aún varios casos y se hicieron positivos dos que al estudio de la conización, uno dio metaplasia escamosa y regresó al tipo II, y el otro dio carcinoma pavimentoso.

Tuvimos un caso de este mismo grupo al cual, al mismo tiempo, se le tomó biopsia y resultó ser carcinoma.

En el grupo IV encontramos lo siguiente:

Cuatro casos se hicieron negativos en controles posteriores.

Diez están aún en control.

Seis no regresaron.

El resto, es decir diez y nueve, muchos de ellos con lesión clínicamente sospechosa, resultaron ser carcinomas.

\section{TIPO IV}

Número de casos:

Se hicieron negativos:

Aún en control:

No regresaron:

Resultaron carcinomas:

En los tipo V se encontró carcinoma en veintiuno; algunos con lesión carcinomatosa franca, y otros, seis de ellos, con cuello clínicamente sano. De estos seis últimos, cuatro presentaban sintomatología (flujo, sinusorragia etc.), y dos, ningún síntoma.

A los casos con cuello sano, se les practicó conización, y en cortes seriados se confirmó el diagnóstico. A los demás simple biopsia.

En los dos casos restantes de este grupo tipo V no se confirmó el diagnóstico de carcinoma, pero en controles posteriores desaparecieron las atipias y regresaron a tipo II, lo que demuestra que la lesión inicial desapareció con la conización y talvez un mayor número de cortes hubiera podido demostrar la lesión carcinomatosa. 
Número de casos:

Carcinomas comprobados:

Carcinomas no comprobados:

Cuello clínicamente sano:

Con síntomas:

Sin síntomas:

En este trabajo los casos más demostrativos de la utilidad de la citología están en el grupo V con cuello clínicamente sano y que dieron carcinoma.

En dos pacientes en la pieza operatoria (Histerectomía tipo Wertheim), no se encontró el carcinoma, lo que demuestra que desapareció con la sola conización.

Como contraprueba todavía más evidente del valor de la citología en el diagnóstico del carcinoma de cuello uterino, podemos relatar dos casos en los cuales la citología se mantuvo en el tipo II, a pesar de que el informe de la biopsia indicaba la presencia de carcinoma.

Estudio muy cuidadoso de esta aparente contradicción, reveló finalmente que la citología era la verdadera, y que la interpretación de las preparaciones histológicas, no correspondía a carcinoma. Uno de los casos era una metaplasia escamosa, y el otro una atipia menor debida a un proceso inflamatorio crónico.

También hemos tenido varios casos de citología persistentemente positiva, con biopsia múltiple negativa.

Creemos pues, que en presencia de citología positiva con cuello sano, la mejor conducta es practicar de una vez la conización y cortes seriados, ya que, ni la biopsia múltiple puede descubrir en muchos casos el carcinoma. 


\section{CONCLUSIONES}

1) La citología exfoliativa es actualmente el método más seguro para el diagnóstico precoz del carcinoma genital de la mujer.

2) La biopsia simple o por conización, son apenas métodos confirmatorios de lo que la citología exfoliativa está en condiciones de diagnosticar tempranamente.

3) En casos de citología persistentemente positiva y biopsias persistentemente negativas, se está autorizado a darle más crédito a la primera.

4) Nadie puede descartar la presencia de carcinoma por el solo examen clínico del cuello. Es imperativo un control citológico siquiera anual a toda paciente que pase por la consulta ginecológica, aunque lo ideal sería hacerlo en todas las mujeres, especialmente en aquellas mayores de 30 años.

5) Es necesario crear en la conciencia de todos los médicos la idea de que la mejor solución al problema de la lucha contra el cáncer es su diagnóstico precoz, el cual sólo se logra por medio de la Citología exfoliativa en la inmensa mayoría de los casos, practicada como procedimiento de rutina. 